\title{
Evaluation of the efficacy of sodium valproate in convulsive status epilepticus following to Ischemic stroke
}

\author{
Avaliação da eficácia do valproato de sódio no status epilepticus convulsivo devido ao \\ acidente vascular cerebral isquêmico
}

Hasan Hüseyin Özdemir', Bülent Müngen², Selçuk Ilhan ${ }^{3}$

\begin{abstract}
Objective: Convulsive status epilepticus (CSE) is very rarely observed after ischaemic stroke. Sodium valproate (SV) is one of the agents used in the treatment of CSE, but its role still controversial, and its degree of efficacy in treating CSE that develops following stroke is unclear. Method: We evaluated 19 patients who were treated with intravenous (IV) SV (20 mg/kg, 2 mg/kg/h-12h) after diazepam. Patients' modified Rankin scores (mRS), SE types, and changes in biochemical parameters after treatment were assessed. Results: CSE was successfully treated in 12 (63.15\%) patients. Side effects such as hypotension and allergic reactions were observed in two patients. Refractory SE development was observed in 5 (29.4\%) patients with high mRS (> 3). No significant deterioration in patients' laboratory evaluations, conducted before and after status, was observed. Conclusion: SV may be safe and effective in the treatment of CSE observed after ischaemic stroke, especially in patients with low mRS.
\end{abstract}

Keywords: convulsive status epilepticus, ischaemic stroke, sodium valproate.

\section{RESUMO}

Objetivo: Status epilepticus convulsivo (SEC) é muito raramente observado após acidente vascular cerebral isquêmico. Valproato de sódio (VS) é um dos agentes utilizados no tratamento do SEC, mas seu papel ainda é controverso e seu grau de eficácia não é claro no SEC pós acidente vascular. Método: Avaliamos 19 pacientes que foram tratados com AV endovenoso (EV) (20 mg/kg, 2 mg/kg/h-12h) após diazepam. Valores da escala modificada de Rankin (mRS) dos pacientes, tipos de SE e mudanças nos parâmetros bioquímicos foram avaliados. Resultados: SEC foi tratado com sucesso em 12 pacientes (63,15\%). Efeitos colaterais como hipotensão e reações alérgicas foram observados em dois pacientes. Desenvolvimento de SE refratário foi observado em cinco pacientes (29,4\%) com altos valores de mRS (> 3). Não houve deterioração significativa nas avaliações laboratoriais dos pacientes feitas antes ou depois do status. Conclusão: AV pode ser eficaz no tratamento do SEC observado após acidente vascular cerebral isquêmico, especialmente nos pacientes com baixo mRS.

Palavras-chave: status epilepticus convulsivo, acidente vascular cerebral isquêmico, valproato de sódio.

Stroke has long been recognised as a common cause of epileptic seizures, and indeed is the most common cause of seizures in adults aged $\geq 60^{1}$. Previous studies have shown that the frequency of seizures in stroke ranges between 2.3\% and $19 \%^{2,3,4,5}$.The outcome for patients having early-onset seizures is poor, with a high in-hospital mortality rate and a high incidence of status epilepticus (SE) ${ }^{6}$. Therefore, the role of stroke as an aetiological factor in SE is accepted ${ }^{2}$. SE is primarily observed in patients with a severe stroke. It can be a presenting symptom of acute stroke, and almost half of adult
SE cases are caused by combined acute and remote symptomatic cerebrovascular disorders ${ }^{1}$. SE occurs in $20.7 \%$ of patients at stroke onset, in $11.7 \%$ of patients at late-onset and at very late-onset in only $2.1 \%$ of patients ${ }^{7}$. In addition, stroke patients suffering from SE have worse outcomes than patients who do not experience seizures, and mortality rates in stroke patients with SE can also be higher ${ }^{3,4}$.

There are several challenges when treating stroke patients with SE, including increased mortality, concomitant diseases, lack of evidence supporting the use of various treatment

'Dicle University Neurology, Diyarbakır, Turkey;

${ }^{2}$ Fırat University Neurology, Elazı̆̆, Turkey;

${ }^{3}$ Fırat University Pharmacology Department, Elazı̆̆, Turkey.

Correspondence: Hasan Hüseyin Özdemir; Dicle University Neurology; 21280 Diyarbakır, Turkey; E-mail:drhasanh@gmail.com

Conflict of interest: There is no conflict of interest to declare.

Received 26 May 2014; Received in final form 11 November 2014; Accepted 01 December 2014. 
options and a high rate of adverse effects. Therefore, treatment of epileptic seizures and SE is very important in patients who have suffered strokes, and such treatment should be rapid-acting and with few side effects.

Convulsive status epilepticus (CSE) is the most common and life-threatening form of $\mathrm{SE}^{6}$. It is observed in $0.2 \%$ of patients after ischaemic stroke, and occurs more often than nonconvulsive $\mathrm{SE}^{4,8}$. Several studies have shown that intravenous (IV) sodium valproate (SV) is effective in the treatment of CSE, although the correct dose to administer when treating repetitive seizures remains controversial ${ }^{9,10}$. Previous studies that have evaluated the efficacy of SV in treating SE have described various causes of SE; there is no clear evidence regarding the SE that develops during the acute period after ischaemic stroke. Moreover, the efficacy of SV in the treatment of CSE that develops after stroke has not been fully elucidated. Therefore, in this study, we evaluated the efficacy of SV in treating CSE that develops in the acute period following stroke.

\section{METHOD}

The study population was derived from the SE Data Bank of Frrat University Hospital, Turkey, and this included all SE patients $(n=151)$ admitted to the hospital from January 2007 to October 2013. This hospital-based data bank included information regarding the duration and type of SE, underlying factors, such as structural deficits or medical pathologies, and demographic data. We included only patients who had experienced ischaemic stroke, and excluded patients with a history of seizure, pseudoseizures, nonconvulsive SE, subarachnoid haemorrhage, head injury, hypertensive and metabolic encephalopathy, diabetic ketoacidosis, acute/chronic renal and liver failure, malignant hypertension, arteritis, fever and cerebrovenous thrombosis. As a result, we included only 19 of the 151 identified patients.

All patients underwent a CT scan at admission, a second scan after 24-72 $\mathrm{h}$ and further scans when necessary. All patients with ischaemic stroke were investigated using Doppler carotid ultrasonography, transthoracic echocardiography, and 24-hour holter electrocardiography if a cardioembolic stroke was suspected. In all patients, liver function and whole blood tests, plasma urea, creatinine, electrolyte and plasma glucose levels were measured on admission and after $48 \mathrm{~h}$.

An experienced neurologist evaluated neurological deficits on admission. The degree of functional disability was graded using a modified Rankin scale (mRS) before SE, but only one patient's mRS was graded after SV treatment ${ }^{11}$. In addition, patients were again evaluated during hospital discharge (outcome).

The diagnosis was based on direct observation of seizures by the medical staff at the time of hospitalisation, the patient's history provided by his or her neurologist, reliable descriptions obtained from ambulance personnel when seizures occurred during transportation, or on observations of close family members when seizures occurred at home.

According to the 1981 classification criteria, CSE was divided into generalized convulsive status epilepticus (GCSE), complex partial secondary-generalised convulsive status epilepticus (CPS-GCSE), and tonic status epilepticus (TSE) ${ }^{12}$. In addition, patients with refractory status epilepticus (RSE) were identified ${ }^{12}$.

Diazepam (DZP) was given at a rate of $10 \mu \mathrm{g} / \mathrm{kg} / \mathrm{min}$ and was increased by $10 \mu \mathrm{g} / \mathrm{kg} / \mathrm{min}$ every $5 \mathrm{~min}$ until SE control or a maximum dose of $100 \mu \mathrm{g} / \mathrm{kg} / \mathrm{min}$ was reached. After DZP treatment, $20 \mathrm{mg} / \mathrm{kg}$ in $100 \mathrm{ml}$ of IV saline-infused SV was administered over $15 \mathrm{~min}$, following which, a loading dose/continuous infusion was administered at a rate of $2 \mathrm{mg} / \mathrm{kg} / \mathrm{h}$ as the maintenance dose for $12 \mathrm{~h}$. After discontinuation of IV infusion, a maintenance IV dose of $400 \mathrm{mg}$ every 8 h was continued. Refractory status epilepticus (RSE) was accepted as a diagnosis for continuous seizures not responsive to DZP and SV.

Adverse local effects (burning, pain and phlebitis at injection site) and systemic effects (low blood pressure, heart rate disorder and respiratory suppression) were also monitored. All patients also received general medical management, including oxygen, cooling, electrolyte balancing, prevention of complications and other symptom-relief treatment, such as mannitol, acetyl salicylic acid, and clopidogrel. None of the patients were administered t-PA.

EEG recording devices were not appropriate in some circumstances so EEG was performed 6 to 48 hours. All patient's therapy was started clinically. An EEG was carried out at the end of seizure for 15 patients, during seizure for two patients, and two patients did not undergo an EEG. EEGs were considered abnormal when burst-suppression pattern, focal, lateralised or generalised slowing or epileptiform discharges were present.

The stopping of SE table in patients was confirmed by the clinical cessation of seizure activity. In addition, in order to electrographically evaluate nonconvulsive SE, EEG was carried out using a device in the intensive care unit.

\section{Statistical analysis}

Analysis of data was carried out using SPSS 21.0. For continuous variables such as age and time of start of SE, descriptive statistics were calculated and reported as mean \pm SD. The paired t-test was used to compare the values of means.

\section{RESULTS}

A total of 19 patients were deemed eligible for, and were included in, the study. Cardioembolic stroke was observed in seven patients, and large artery atherosclerosis was observed in 12 patients $^{13}$. 
We found that seven patients had GCSE, 10 had CPS-GCSE and two had TSE. The mean age of the patients was $71.05 \pm 11.0$ (age: 58-90 years). Infarct was observed in the entire hemisphere to $A$. carotis interna stenose in two patients, at the $A$. cerebri media (MCA) region in 13 patients, and in the temporal regions in four patients (Table 1).

We observed an allergic reaction during the SV infusion in one patient, and a significant decrease in blood pressure in a different patient. The infusion was discontinued in these two patients, and they were excluded from the study. Of the patients who completed the study, 10 were female and seven were male.

We found that SV treatment halted SE in $63.15 \%$ (12) of the patients. Following the development of ischaemic stroke, the onset of SE was $33.55 \pm 26.75$ hours. The average of $\mathrm{mRS}$ before $\mathrm{SE}$ was $3.21 \pm 1.22$, and outcome mRS was $3.23 \pm 1.09$. The average time it took for SV to control SE was $17.91 \pm 4.98 \mathrm{~min}$.

RSE developed in five of the patients, and two of them died. Of the five patients in whom RSE was detected, the Rankin score was 5 in four of the patients and 4 in one patient. Infarct was observed in the left hemisphere of four of five patients in whom RSE developed, and in the right hemisphere of one patient.
EEG findings revealed periodic lateralising epileptiform abnormalities in six patients, focal slowing in five patients, generalised slowing in four patients and a burst-suppression pattern in two patients.

We observed an increase in alanine aminotransferase, aspartate aminotransferase and ammonia values, a decrease in glucose, platelets and sodium values and no statistically significant differences in patients' white blood cell and amylase levels. However, we did not observe deterioration in liver and kidney function tests, thrombocytopenia, and hyponatremia (Table 2).

\section{DISCUSSION}

In the present study, SV treatment halted SE in 12 (63.15\%) patients. Some previous studies have shown that there is no relationship between the occurrence of SE and gender, age, stroke risk factors, stroke type (ischaemic or haemorrhagic), stroke topography and stroke cause, cortical involvement or size of lesion in patients with stroke ${ }^{14}$. However, damage to the cerebral cortex is widely considered to be a sine qua non for the development of epilepsy, and indeed epilepsy is rare in

Table 1. Demographic characteristics of patients.

\begin{tabular}{|c|c|c|c|c|c|c|}
\hline Patient-Age/ Gender & Lesion & $\begin{array}{l}\text { Before treatment } \\
\text { mRS/ Outcome mRS }\end{array}$ & $\begin{array}{c}\text { Risk } \\
\text { factors }\end{array}$ & $\begin{array}{l}\text { Status epilepticus starting } \\
\text { time (after ischemia) }\end{array}$ & $\begin{array}{l}\text { Type of status } \\
\text { epilepticus }\end{array}$ & $\begin{array}{l}\text { Time to seizure } \\
\text { controlled (min) }\end{array}$ \\
\hline $1-85 F$ & Left MCA infarction & $2 / 3$ & $\mathrm{DM}, \mathrm{HT}$ & $48 \mathrm{~h}$ & CPS-GCSE & 15 \\
\hline $2-60 F$ & $\begin{array}{l}\text { Right temporal lobe } \\
\text { infarction }\end{array}$ & $2 / 2$ & $A F$ & $36 \mathrm{~h}$ & CPS-GCSE & 15 \\
\hline $3-58 M$ & Left MCA infarction & $4 / 4$ & $\mathrm{AF}$ & $72 \mathrm{~h}$ & GCSE-RSE & 30 \\
\hline $4-58 \mathrm{~F}$ & Right MCA infarction & $3 / 3$ & $A F$ & $6 \mathrm{~h}$ & CPS-GCSE & 20 \\
\hline $5-83 M$ & Right MCA infarction & $3 / 4$ & DM & $12 \mathrm{~h}$ & CPS-GCSE & 20 \\
\hline $6-75 M$ & Right MCA infarction & $3 / 3$ & $\mathrm{DM}, \mathrm{HT}$ & $96 \mathrm{~h}$ & TSE & 15 \\
\hline $7-63 F$ & $\begin{array}{l}\text { Left temporal lobe } \\
\text { infarction }\end{array}$ & $2 / 2$ & $A F$ & $24 \mathrm{~h}$ & CPS-GCSE & 15 \\
\hline $8-60 F$ & $\begin{array}{l}\text { Right temporal lobe } \\
\text { infarction }\end{array}$ & $2 / 2$ & AF & $10 \mathrm{~h}$ & CPS-GCSE & 20 \\
\hline $9-75 F$ & Right MCA infarction & $2 / 2$ & DM, HT & $72 \mathrm{~h}$ & CPS-GCSE & 20 \\
\hline $10-62 F$ & $\begin{array}{l}\text { Right temporal lobe } \\
\text { infarction }\end{array}$ & $2 / 2$ & $A F$ & $36 \mathrm{~h}$ & CPS-GCSE & 10 \\
\hline $11-73 F$ & Right MCA infarction & $3 / 3$ & DM, HT & $6 \mathrm{~h}$ & TSE & 15 \\
\hline $12-58 M$ & Left MCA infarction & $3 / 3$ & $\mathrm{DM}, \mathrm{AF}$ & $48 \mathrm{~h}$ & CPS-GCSE & 20 \\
\hline $13-81 F^{\#}$ & Left MCA infarction & $5 / 5$ & $\mathrm{DM}, \mathrm{HT}$ & $10 \mathrm{~h}$ & GCSE-RSE & 35 \\
\hline $14-62 F^{\#}$ & Right MCA infarction & $5 / 5$ & $A F$ & $36 \mathrm{~h}$ & CPS-GCSE & 30 \\
\hline $15-82 \mathrm{M}^{\#}$ & Left MCA infarction & $5 / 5$ & DM, HT & $36 \mathrm{~h}$ & GCSE-RSE & 50 \\
\hline $16-90 \mathrm{M} \#$ & $\begin{array}{l}\text { Right hemisphere } \\
\text { infarction }\end{array}$ & $5 * /-$ & $\mathrm{DM}, \mathrm{HT}$ & $30 \mathrm{~min}$ & $\begin{array}{l}\text { GCSE-RSE } \\
(\mathrm{ex})\end{array}$ & - \\
\hline $17-85 \mathrm{M}^{\#}$ & $\begin{array}{l}\text { Left hemisphere } \\
\text { infarction }\end{array}$ & $5 /-$ & $\mathrm{DM}, \mathrm{HT}$ & $1 \mathrm{~h}$ & $\begin{array}{l}\text { GCSE-RSE } \\
(\mathrm{ex})\end{array}$ & - \\
\hline $18-75 F$ & $\begin{array}{l}\text { Right MCA infarction } \\
\text { (allergic reactions) }\end{array}$ & $2 / 3$ & HT & $48 \mathrm{~h}$ & GCSE & 25 \\
\hline $19-65 \mathrm{~F}$ & $\begin{array}{l}\text { Right MCA infarction } \\
\text { (hypotension) }\end{array}$ & $3 / 4$ & DM & $40 \mathrm{~h}$ & GCSE & 30 \\
\hline
\end{tabular}

DM: Diabetes mellitus; HT: Hypertension; SE: Status epilepticus; mRS: Modified Rankin scores; AF: Atrial fibrillation; GCSE: Generalized convulsive status epilepticus; CPS-GCSE: Complex partial secondary-generalized convulsive status epilepticus; TSE: Tonic status epilepticus; MCA: Middle cerebral artery; h: Hour; min: Minute; \# Status epilepticus did not stop giving SV; * After SV treatment. 


\begin{tabular}{lccc}
\hline & Pretreatment $(\mathrm{n}=17)$ & Post-treatment $(48 \mathrm{~h})(\mathrm{n}=17)$ & $\mathrm{p}$-value \\
\hline Glucose $(75-115 \mathrm{mg} / \mathrm{dL})$ & $158.88 \pm 70.17$ & $117.58 \pm 42.40$ & 0.013 \\
WBC (3.5-10.5 billion/L) & $9.2 \pm 1158$ & $9.3 \pm 1254$ & $>0.05$ \\
PLT (150-450 billion/L) & $361.82 \pm 115.65$ & $336.94 \pm 105.59$ & 0.045 \\
ALT (7-55 U/L) & $41.05 \pm 9.01$ & $55.76 \pm 14.57$ & 0.001 \\
AST (7-55 U/L) & $40.88 \pm 8.29$ & $54.41 \pm 19.36$ & 0.003 \\
Ammonia (15-60 mcg/dL) & $36.00 \pm 13.24$ & $41.58 \pm 10.86$ & 0.002 \\
K (3.6-5.5 mmol/L) & $4.16 \pm 0.68$ & $3.96 \pm 0.76$ & $>0.05$ \\
Na (135-145 mEq/L) & $141.76 \pm 4.17$ & $140.70 \pm 3.92$ & 0.015 \\
Amilase (23-85 U/L) & $80.88 \pm 27.90$ & $83.41 \pm 27.46$ & $>0.05$ \\
Soyum Valproat (50-100 mg/L) & - & $83.29 \pm 18.42$ & \\
\hline
\end{tabular}

WBC: White blood cells; ALT: Alanine Aminotransferase; PLT: Platelet; AST: Aspartate Aminotransferase; K: Potassium; Na: Sodium.

strokes that occur in the posterior fossa or deep white matter $^{14}$. Several studies have shown that cortical involvement is a risk factor independent of infarct size; in other studies it was associated with large infarcts ${ }^{15,16}$. In our study, we observed infarct in an entire hemisphere in two patients, in the region corresponding to the irrigation area of MCA in 13 patients, and in the temporal regions in four patients. Our findings may indicate that a large infarct area, including the temporal region, may be important for the development of SE. Likewise, infarct was shown in the left hemisphere in four of five patients in whom RSE developed, and in the right hemisphere in one patient. We more frequently observed RSE in patients with left hemisphere lesions. However, we cannot speculate on the possible causes of this, since many factors contribute to the development of RSE.

Rankin scale is very important in the assessment of disability in patients with stroke ${ }^{11}$. Our patients' outcome average mRS had increased in a similar manner to that reported in previous studies ${ }^{3,4}$. In addition, we found that the patients with high mRS did not adequately respond to IV SV treatment, and the development of RSE occurred more frequently in these patients; those patients with low mRS responded far better to this treatment.

RSE occurs in up to $44 \%$ of all patients with $\mathrm{SE}^{17}$. The mortality of RSE is at least $16 \%-23 \%$, and again depends on age and aetiology ${ }^{18}$. It is treated with coma induction using anaesthetics such as propofol or barbiturates. RSE developed in five of our patients, two of whom died.

The National Institutes of Health warn patients taking SV about the risk of serious or life-threatening damage to the liver and pancreas that is associated with the use of this drug ${ }^{19}$. Case presentations have shown that SV causes hypotension and allergies, but that it is a safe and effective drug, despite these side effects ${ }^{10,20,21}$. In our study, two patients developed hypotension and hypersensitivity reactions. However, many complications developed in SE, and changes in metabolic parameters were also monitored during the course of stroke. Although changes were statistically observed in some parameters in the assessment carried out $48 \mathrm{~h}$ after treatment, thrombocytopenia and hyponatremia with liver dysfunction and liver failure did not develop in any of the patients in our study.

Phenytoin is recommended as the first-line antiepileptic drug for SE, and its metabolism may be affected by other drugs, which increase phenytoin blood levels and toxicity ${ }^{22}$. Tiamkao et al. showed that the time to seizure control and number of non-dependent patients was increased, and duration of hospitalisation and number of deaths was reduced, with SV treatment compared to phenytoin treatment. In our study, the average time at which SV halted SE was similar to that observed in their study. In addition, these authors reported that SV is non-inferior to intravenous phenytoin as the first-line treatment in SE, with no significant cardiovascular compromises, and that SV may be used in elderly patients with cardiovascular risks or hepatitis ${ }^{10}$. Moreover, having little interaction with other drugs and with linear kinetics, SV has an advantage over phenytoin in this respect. SV may be also similarly be more effective and safe than phenytoin in the elderly with SE.

Our study had some limitations. It was a retrospective study, and the number of patients used was small. In addition, EEG was not performed at the start of seizures, meaning that SE was evaluated more clinically than electrographically.

Development of SE after ischaemic stroke is a very rare condition that may be associated with numerous factors. According to our observations, SV may be effective in the treatment of CSE that develops during the acute period after ischaemic stroke, especially in patients with a low mRS. However, strict monitoring should be conducted with regard to hypersensitivity and hypotension. In addition, we observed that SV was less effective in the treatment of RSE, but that RSE was more frequently identified in patients with a high mRS. 


\section{References}

1. DeLorenzo RJ, Hauser WA, Towne AR, Boggs JG, Pellock JM, Penberthy L, et al. A prospective, population-based epidemiologic study of status epilepticus in Richmond, Virginia. Neurology. 1996;46(4):1029-35. http://dx.doi.org/10.1212/WNL.46.4.1029

2. Lowenstein DH, Alldredge BK. Status epilepticus at an urban public hospital in the 1980s. Neurology. 1993;43(3 Pt 1):483-8. http://dx.doi.org/10.1212/WNL.43.3_Part_1.483

3. De Reuck j, Claeys I, Martens S, Vanwalleghem P, Van Maele G, Phlypo R, et al. Computed tomographic changes of the brain and clinical outcome of patients with seizures and epilepsy after an ischaemic hemispheric stroke. Eur J Neurol. 2006;13(4):402-7. http://dx.doi.org/10.1111/j.1468-1331.2006.01253.x

4. Rumbach L, Sablot, D, Berger E, Tatu L, Vuillier F, Moulin T. Status epilepticus in stroke: report on a hospitalbased stroke cohort. Neurology. 2000;54(2):350-4. http://dx.doi.org/10.1212/WNL.54.2.350

5. Menon B, Shorvon SD. Ischaemic stroke in adults and epilepsy. Epilepsy Res. 2009;87(1):1-11.http://dx.doi.org/10.1016/j.eplepsyres.2009.08.007

6. De ReuckJ, Van Maele G. Status epilepticus in stroke patients. Eur Neurol. 2009b:62(3):171-5. http://dx.doi.org/10.1159/000227289

7. De Reuck J. Management of stroke-related seizures. Acta Neurol Belg. 2009;109(4):271-6.

8. Bateman BT, Claassen J, Willey JZ, Hirsch LJ, Mayer SA, Sacco $\mathrm{RL}$ et al. Convulsive status epilepticus after ischemic stroke and intracerebral hemorrhage: frequency, predictors, and impact on outcome in a large administrative dataset. Neurocrit Care. 2007;7(3):187-93. http://dx.doi.org/10.1007/s12028-007-0056-2

9. Misra UK, Kalita J, Patel R. Sodium valproate vs phenytoin in status epilepticus: a pilot study. Neurology. 2006;67(2):340-2. http://dx.doi.org/10.1212/01.wnl.0000224880.35053.26

10. Tiamkao S, Sawanyawisuth K, Chancharoen A. The efficacy of intravenous sodium valproate and phenytoin as the first-line treatment in status epilepticus: a comparison study. BMC Neurol. 2013;27;13:98. http://dx.doi.org/10.1186/1471-2377-13-98

11. Wolfe CD, Taub NA, Woodrow EJ, Burney PG. Assessment of scales of disability and handicap for stroke patients. Stroke. 1991;22(10):1242-4. http://dx.doi.org/10.1161/01.STR.22.10.1242
12. Commission on Classification and Terminology of the International League Against Epilepsy. Proposal for revised clinical and electro-encephalographic classification of epileptic seizures. Epilepsia. 1981;22(4):489-501. http://dx.doi.org/10.1111/j.1528-1157.1981.tb06159.x

13. Kolominsky-Rabas PL, Weber M, Gefeller O, Neundoerfer B, Heuschmann PU. Epidemiology of ischemic stroke subtypes according to TOAST criteria. Stroke. 2001;32:2735-40. http://dx.doi.org/10.1161/hs1201.100209

14. Velioğlu SK, Özmenoğlu M, Boz C, Alioğlu Z. Status epilepticus after stroke. Stroke. 2001;32(5):1169-72. http://dx.doi.org/10.1161/01.STR.32.5.1169

15. Bladin CF, Alexandrov AV, Bellavance A, Bornstein N, Chambers B, et al. Seizures after stroke: a prospective multicenter study. Arch Neurol. 2000;57(11):1617-22. http://dx.doi.org/10.1001/archneur.57.11.1617

16. Kilpatrick CJ, Davis SM, Tress BM, Rossiter SC, Hopper JL, Vandendriesen ML. Epileptic seizures in acute stroke. Arch Neurol. 1990;47(2):157-60. http://dx.doi.org/10.1001/archneur.1990.00530020053014

17. Yaffe K, Lowenstein DH. Prognostic factors of pentobarbital therapy for refractory generalized status epilepticus. Neurology. 1993;43(5):895-900. http://dx.doi.org/10.1212/WNL.43.5.895

18. Holtkamp M, Othman J, Buchheim K, Meierkord H. Predictors and prognosis of refractory status epilepticus treated in a neurological intensive care unit. J Neurol Neurosurg Psychiatry. 2005;76(4):534-9. http://dx.doi.org/10.1136/jnnp.2004.041947

19. Nanau RM, Neuman MG. Adverse drug reactions induced by valproic acid. Clin Biochem. 2013;46(15):1323-38. http://dx.doi.org/10.1016/j.clinbiochem.2013.06.012

20. Bota RG, Ligasan AP, Najdowski TG, Novac A. Acute hypersensitivity syndrome caused by valproic Acid: a review of the literature and a case report. Perm J 2011;15(2):80-4.

21. Ota KS. Probable valproate sodium-associated hypotension. Am J Geriatr Pharmacother. 2010;8(3):281-4. http://dx.doi.org/10.1016/j.amjopharm.2010.04.005

22. Drugs for epilepsy. Treat Guidel Med Lett. 2008;6(70):37-46. 